\title{
Adenoid basal carcinoma of the cervix uteri ${ }^{1}$
}

\author{
K. B. SHILKIN
}

From the Department of Pathology, University of Singapore, Singapore

SYNOPSIS This paper describes a case of adenoid basal carcinoma of the uterine cervix, occurring in a woman aged 78 years. In view of the rarity and the limited knowledge of this group of neoplasms, details of the clinical history, the histological appearances, and the histochemical reactions are presented. An attempt is made to define the histogenesis of the tumour and some points on nomenclature are discussed. It is suggested that the tumour arises from multipotential cervical basal cells and that the adenoid structures rather than being true glands are formed by degeneration of the connective tissue stroma. On the basis of a review of reported cases it seems possible that this tumour will be shown to be one of low-grade malignancy.

In recent years an unusual and rare type of tumour of the uterine cervix has been described. Its histological features are distinctive and different from previously recognized epithelial tumours of this site. Brief mention of this class of neoplasm is made in a standard text (Novak and Woodruff, 1967) where the title 'adenoid basal carcinoma', subtitled parenthetically as 'cylindroma', is used. Further confusion concerning nomenclature is apparent in the medical literature where the tumour has been labelled variously as cylindroma (Tchertkoff and Sedlis, 1962), adenoid cystic (pseudoadenomatous) basal cell carcinoma (Gould, Hinerman, Batsakis, and Beamer, 1963), squamous and adenoid cystic basal cell carcinoma (Moss and Collins, 1964), adenoid cystic carcinoma (Bell, 1971; Benitez, Rodriguez, Rodriguez-Cuevas, and Barbosa Chávez, 1969; Dahlin, 1966; Grafton, Willis, Martin, and Mathews, 1968; McGee, Flowers, and Tatum, 1965), and adenoid-basal carcinoma (Baggish and Woodruff, 1966). A total of 12 cases have been documented. Whether these 12 tumours are identical is difficult to assess, nevertheless they appear to comprise a separate group of neoplasms of the cervix. Their histogenesis is open to speculation and is likely to remain uncertain until more tumours of this type are studied.

The purpose of this report is to describe a further example of what is preferably termed, for reasons to be presented, an 'adenoid basal carcinoma'. The clinical, histopathological, and histochemical features are described and some aspects of histogenesis are discussed.

${ }^{1}$ Address for reprints: Dr K. B. Shilkin, Department of Morbid Anatomy, King's College Hospital Medical School, Denmark Hill, London SE5, UK.

Received for publication 21 October 1971.

\section{Case Report}

The patient was a 78-year-old Chinese who complained of vaginal bleeding for four days. She had borne three children and since the menopause, many years previously, had no gynaecological symptoms other than that with which she now presented. Examination of the cervix revealed a polypoid mass of $3 \mathrm{~cm}$ involving and protruding from the external os. Both anterior and posterior lips of the cervix were distended by the tumour. The body of the uterus was not affected, being small and mobile. The pelvic adnexal structures were normal. No further relevant features were found on general examination. Clinically, she was regarded as having carcinoma of the cervix, early stage II. A small biopsy of the mass was reported as malignant, prompting a second procedure to remove, per vagina, as much of the tumour as was easily accessible. Subsequently a short course of deep $x$-ray therapy was given, followed by two insertions of radium, each of $20 \mathrm{mg}$ for 72 hours, at an interval of one week. One year after her first admission to hospital she again had vaginal bleeding. The lumen of the uterus, including the cervical part, was now eroded and contained soft tumour tissue, confirmed histologically. Local extension was not detected and it was thought she did not have metastases. Another course of radiotherapy was given. She died at home three months later, some 16 months from the first onset of symptoms. A necropsy was not performed and the exact cause of death was uncertain.

PATHOLOGY

The initial biopsy was small and reported as a carcinoma, type not specified. The tissue removed at 
the second biopsy was polypoid, soft, white or pale grey, and had several haemorrhagic zones. There were variable and complex microscopic appearances. The major part was made up of a lace-like pattern of trabeculae (Fig. 1) or adenoid formations (Fig. 2) lying in a loose connective tissue stroma. Many of the trabeculae were two cells thick as were the party walls of interconnecting adenoid structures. Sometimes an almost regular honeycomb pattern was formed (Fig. 3). In all these areas the cells were of a fairly uniform basal type, being cuboidal, with a round deeply basophilic nucleus and scant eosinophilic cytoplasm. There were frequent mitoses but otherwise only moderate cellular pleomorphism. The connective tissue was an important component and formed the overall background in which the tumour was embedded. Tongues of stroma protruded into cellular areas and lay on either side of the trabeculae and cell cords. The composition of the centres of the adenoid structures ranged from fibroblastic cellular connective tissue to completely acellular material of a granular or homogeneous mucinous nature. Another different pattern consisted of solid islands of basal cells which aligned at the edges to form a

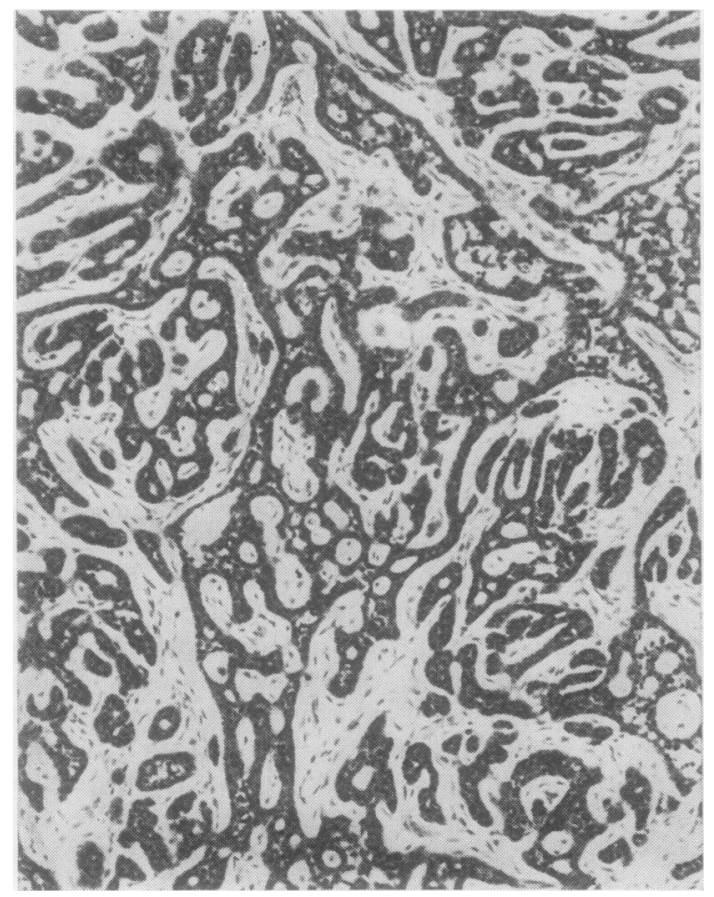

Fig. 1 The tumour in this area has a laciform arrangement of cell cords lying in a loose stroma ( $H$ and $E, \times 106)$. roughly palisaded rim. These areas merged with the $\stackrel{0}{\overrightarrow{0}}$ previously described zones on the one hand and with yet another pattern of more overtly squamous areas $\vec{\Rightarrow}$ on the other. The surface of the tumour also varied, $\stackrel{0}{?}$ with some parts consisting of relatively normal 0 cervical squamous epithelium and others where the $\overline{\bar{O}}$. configuration was similar to that of carcinoma in situ. $\frac{\bar{D}}{7}$ Of particular note were several areas where the neo- $\stackrel{\AA}{\circledR}$ plastic proliferation seemed to arise in the basal layer to extend downwards into the underlying cervical $\overrightarrow{0}$ stroma (Fig. 4). The biopsy taken a year after radiation therapy was of more solid tissue. Again there $\vec{\omega}$ were solid basal cell areas and although adenoid and $\stackrel{\circ}{\circ}$ laciform arrangements were not prominent there $\overline{0}$ were thin cords and small nests of basal type cells. N Squamous areas were again evident.

\section{HISTOCHEMISTRY}

A variety of histochemical techniques were employed 윽 to assess the nature of any intracellular substances and of the material in the centres of the adenoid $\rightarrow$ structures and in the stroma. The methods for mucopolysaccharides have been previously outlined (Tock $\vec{\theta}$ and Shilkin, 1970). Stains for lipids were performed $N$

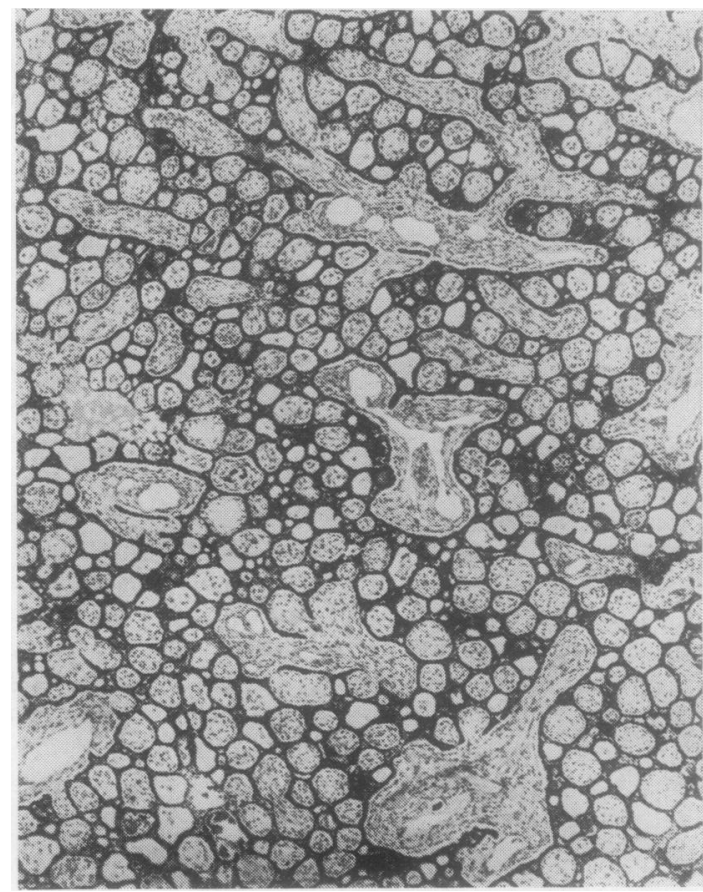

Fig. 2 Adenoid formations are predominant in this area. Most lumens contain stroma, some are acellular $(H$ and $E, \times 46)$. 


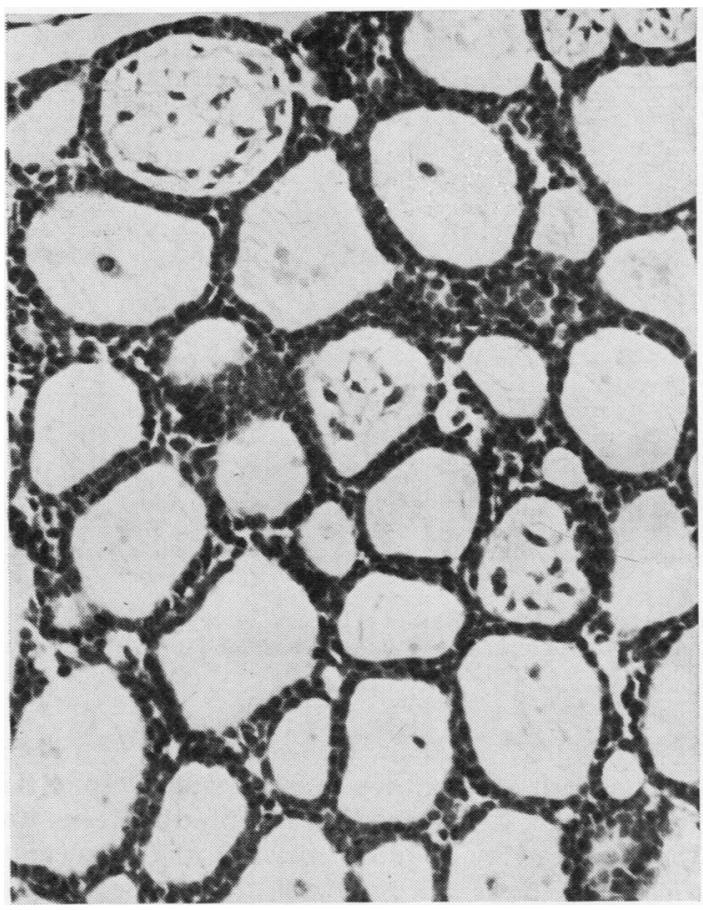

Fig. 3 This is an adenoid area which shows a honeycomb pattern, the double cell nature of the cell cords, and the variation in content of the lumens from cellular stroma to acellular mucinous material ( $H$ and $E, \times 250)$.

on frozen sections of the formalin-fixed tissue. The results are shown in the Table.

Apart from glycogen, which was mainly within the squamous elements but also to a slight extent in the basal cells, there were no intracellular secretory products. The reactions within the adenoid centres and in the stroma were essentially similar with the exception that they were stronger in the former. The material was mainly composed of mucopolysaccharides which were acidic (Alcian blue positive), sulphated (aldehyde-fuchsin positive, toluidine bluemetachromatic) and rich in hyaluronic acid (colloidal iron reaction reduced by pretreatment with testicular hyaluronidase).

\section{Discussion}

Appraisal of the histological and histochemical features of this tumour suggests the likelihood first that the cells are of a basal type and secondly that the mucopolysaccharides both of the ground substance and within the adenoid structures are of connective tissue origin. As the basal cells contain only a little glycogen and do not contain any mucin it is

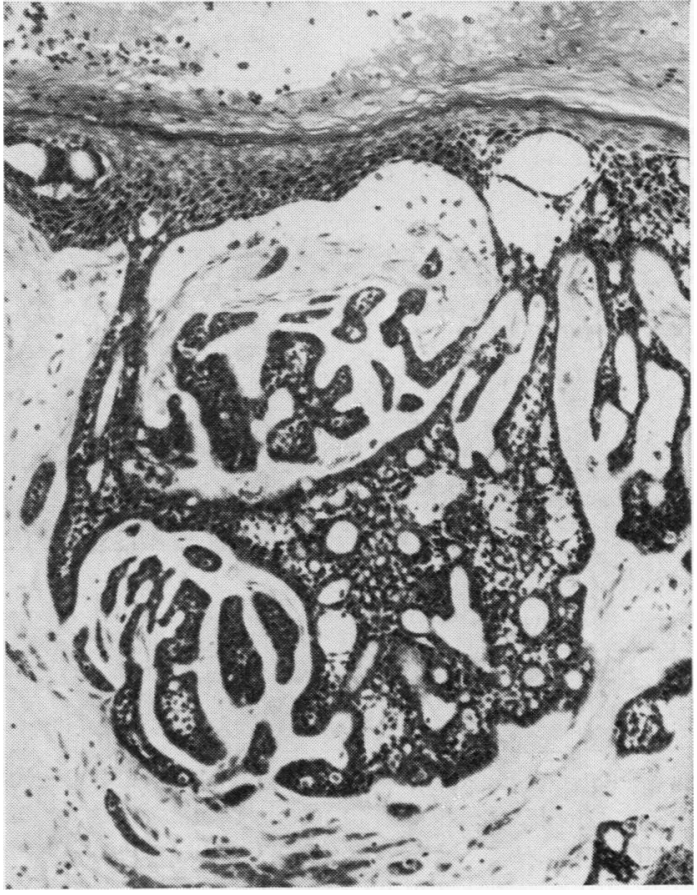

Fig. 4 Here the adenoid basal cell proliferation appears to arise from the basal layer of the overlying cervical squamous epithelium ( $H$ and $E, \times 114)$.

unlikely that they are truly secretory cells or that they are the source of the mucopolysaccharides in the adenoid areas. Such mucopolysaccharides are probably derived from degeneration of connective tissue components which are seen to survive elsewhere. The similarity of histochemical reactions between the mucosubstances in the adenoid structures and in the general stroma reinforces this view.

Histologically the tumour may be regarded as arising from a basal type of cell of the epithelium of the cervix uteri. This cell type would appear to have the ability to produce solid, trabecular, adenoid, and other formations as well as to differentiate along a line towards squamous cells. In this context the cell of origin of the tumour is likely to be an immature one and not to have been derived from malignant transformation of either the differentiated squamous cell or the glandular epithelial cell.

As has been previously suggested by Novak and Woodruff (1967), in its general characteristics the tumour bears most resemblance to the adenoid form of basal cell carcinoma of the skin. It is of interest that these particular skin tumours are sometimes thought to represent differentiation of the neoplastic 


\begin{tabular}{|c|c|c|c|c|}
\hline Stain & Basal Cells & Squamous Cells & $\begin{array}{l}\text { Central Adenoid } \\
\text { Material }\end{array}$ & Stroma \\
\hline PAS & + & ++ & \pm & \pm \\
\hline Pas after diastase & - & - & $\mp$ & $\bar{t}$ \\
\hline MC & - & - & + & + \\
\hline Ast B & - & - & ++ & + \\
\hline AB & - & - & $+t+$ & ++ \\
\hline AB-PAS & - & $\begin{array}{c}++ \\
\text { (red) }\end{array}$ & $\begin{array}{l}+++ \\
\text { (blue) }\end{array}$ & $\begin{array}{l}++ \\
\text { (blue) }\end{array}$ \\
\hline AB after ribonuclease & - & - & +++ & ++ \\
\hline AB after acid hydrolysis & - & - & $++t$ & $+t$ \\
\hline AB after neuraminidase & - & - & $+t+$ & ++ \\
\hline AF & - & - & $+t+$ & + \\
\hline TB $p H 2 \cdot 0$ & & - & $\begin{array}{l}++ \\
\text { (red) }\end{array}$ & $\stackrel{+}{\text { (red) }}$ \\
\hline CI & - & - & $+t+$ & $+t+$ \\
\hline CI after testicular hyaluronidase & & - & + & + \\
\hline Oil Red O & - & - & - & - \\
\hline Sudan Black B & - & - & & - \\
\hline Sudan III and IV & - & - & \pm & \pm \\
\hline
\end{tabular}

Table Histochemical results

The + sign indicates strength of colour reaction: $+++=$ strong; $++=$ moderate; $+=$ weak; $\pm=$ trace; $-=$ negative.

PAS = periodic acid-Schiff; $\mathbf{M C}$ mucicarmine; Ast $\mathbf{B}=$ Astra blue; $\mathbf{A B}=$ Alcian blue; $\mathbf{A F}=$ aldehyde-fuchsin; $\mathbf{T B}=$ toluidine blue; $O$ $\mathrm{CI}=$ colloidal iron.

basal cells towards a sweat gland structure (Lever, 1967). In the cervix, of course, sweat glands do not normally occur. Nevertheless metaplastic reactions to produce sweat glands as well as sebaceous gland and hair follicles do occur on rare occasions (Willis, 1958) and so serve to emphasize the multipotentiality of the cells of the cervical epithelium.

With regard to nomenclature the term adenoid basal carcinoma is to be preferred. As this tumour does not contain myo-epithelial cells and its main cell type is non-secretory it is not identical to the true adenoid cystic carcinomas which occur in the salivary glands and elsewhere. Moreover the mucopolysaccharides of this tumour, being connective tissue in origin, differ from those in the salivary type of tumour where epithelial mucins are prominent (Azzopardi and Smith, 1959). The origin, postulated here, of adenoid basal carcinoma of the cervix from basal cells is in contrast to the histogenesis of adenoid cystic carcinomas which are believed to be derived from the intercalated duct cell (Hoshino and Yamamoto, 1970). Thus the term 'adenoid cystic carcinoma' which has been used in reference to this tumour has several disadvantages. The use of cylindroma is probably also unsound as it is in any case, as Willis (1967) states, a 'meaningless nickname' for the true adenoid cystic carcinoma. Cylindroma of the skin, to which lesion only is this name correctly applied, is a different tumour histomorphologically.

The behaviour of the adenoid basal carcinoma of the cervix is not yet established. Review of the $\mathbf{1 2}$ reported cases does not provide a full picture as adequate long-term follow up has, for several reasons, not always been documented. Despite this it is perhaps significant that in only two cases was there spread of tumour beyond the immediate vicinity of the cervix. In one of these the spread was by direct extension to adjacent pelvic structures and in the other in addition to local pelvic spread there was a solitary metastatic lesion in an axillary lymph node, being the only distant metastasis of the entire reported series. The tumour may well prove to be one of low-grade malignancy.

The author is grateful to Professor K. Shanmugaratnam and Associate Professor E. P. C. Tock for advice, Mr. K. N. Rai for technical help, and Mr. G. Harwood for photography.

\section{References}

Azzopardi, J. G., and Smith, O. D. (1959). Salivary gland tumours and their mucins. J. Path. Bact., 77, 131-140.

Baggish, M. S., and Woodruff, J. D. (1966). Adenoid-basal carcinoma of the cervix. Obstet and Gynec., 28, 213-218.

Bell, J. R. (1970). Adenoid cystic carcinoma of cervix (Abstr.). $N$ Pathology, 3, 60-61.

Benitez, E., Rodriguez, H. A., Rodriguez-Cuevas, H., and Barbosa Chávez, G. (1969). Adenoid cystic carcinoma of the uterine cervix: report of a case and review of four cases. Obstet. and $N$ Gynec., 33, 757-762.

Dahlin, D. C. (1966). 'Case No. 9.' In Proceedings from the Seminar of the Houston Society of Clinical Pathologists.

Gould, S. E., Hinerman, D. L., Batsakis, J. G., and Beamer, P. R. (1963). Diagnostic patterns: lesions of the cervix. Amer. J. clin. Path., 40, 537-540.

Grafton, W. D., Willis, G. W., Martin, J. R., and Mathews, W. R. (1968). Adenoid cystic carcinoma of the cervix: a report of two cases. J. L. med. Soc., 120, 276-277.

Hoshino, M., and Yamamoto, I. (1970). Ultrastructure of adenoid cystic carcinoma. Cancer (Philad.), 25, 186-198.

Lever, W. F. (1967). Histopathology of the Skin, 4th ed., pp. 535-536. Lippincott, Philadelphia. Pitman, London.

McGee, J. A., Flowers, C. E., and Tatum, B. S. (1965). Adenoid cystic 
carcinoma of the cervix. Report of a case. Obstet. and Gynec., 26, 356-358.

Moss, L. D., and Collins, D. N. (1964). Squamous and adenoid cystic basal cell carcinoma of the cervix uteri. Amer.J. Obstet. Gynec., 88, 86-90.

Novak, E. R., and Woodruff, J. D. (1967). Gynecologic and Obstetric Pathology, 6th ed. Saunders, Philadelphia.

Tchertkoff, V., and Sedlis, A. (1962). Cylindroma of the cervix. Amer.

$$
\text { J. Obstet. Gynec., 84, 749-752. }
$$

Tock, E. P. C., and Shilkin, K. B. (1970). Histochemical study of mucosubstances and glycogen of the postmenopausal human cervix uteri. Amer. J. Obstet. Gynec., 107, 194-201.

Willis, R. A. (1958). The Borderland of Embryology and Pathology, pp. 520-552. Butterworth, London.

Willis, R. A. (1967). Pathology of Tumours, 4th ed., p. 327. Butterworth, London. 